\title{
Student Web-Mapping Competition 2009
}

David Heyman | dave@axismaps.com

Axis Maps, LLC

PO Box 421

Hewitt, TX 76643

\section{INTRODUCTION}

The thing that most surprised me when judging the student web-mapping competition was the diversity of the entries. Not only did we have maps sent from universities all over the country, but the students' subject matter, graphic presentation, and interactive techniques really showed the amazing variety that is possible in web maps. The two winners are both excellent examples of their respective categories and show great professionalism and polish, but every entry really opened my eyes to the excellent web-mapping work students are doing today. Although the 2011 NACIS conference may seem a long way off, teachers, please tell your students about this competition today! The maps they create in this current academic year are eligible for the upcoming competition, and we would love to see the great work they have been doing. For complete rules and sub mission guidelines, visit the web site: http://www.nacis.org/index.cfm? $\mathrm{x}=4$
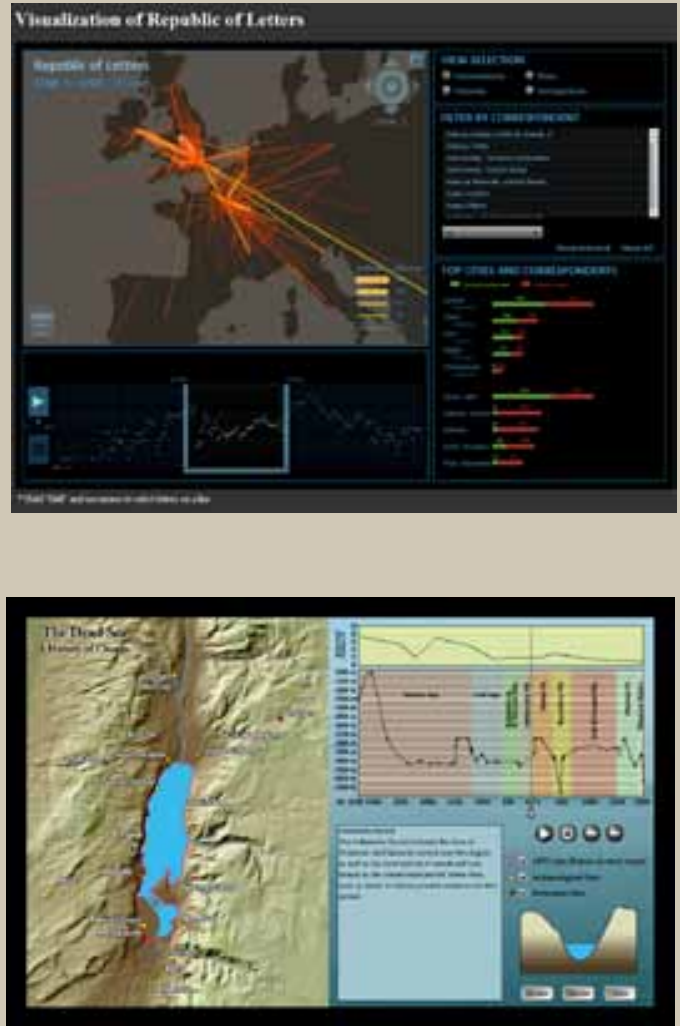

\section{WINNER, INTERACTIVE}

Yuankai Ge, Daniel Chang, and Shiwei Song, Stanford University

"Visualization of the Republic of Letters"

http://stanford.edu/group/toolingup/rplviz/

(Detail on following pages)

\section{WINNER, ANIMATED}

A.D. Riddle and David Parker, University of Wisconsin-Madison "The Dead Sea: A History of Change"

http://deadseachange.webs.com/map.html

(Detail on following pages) 


\section{Visualization of Republic of Letters}

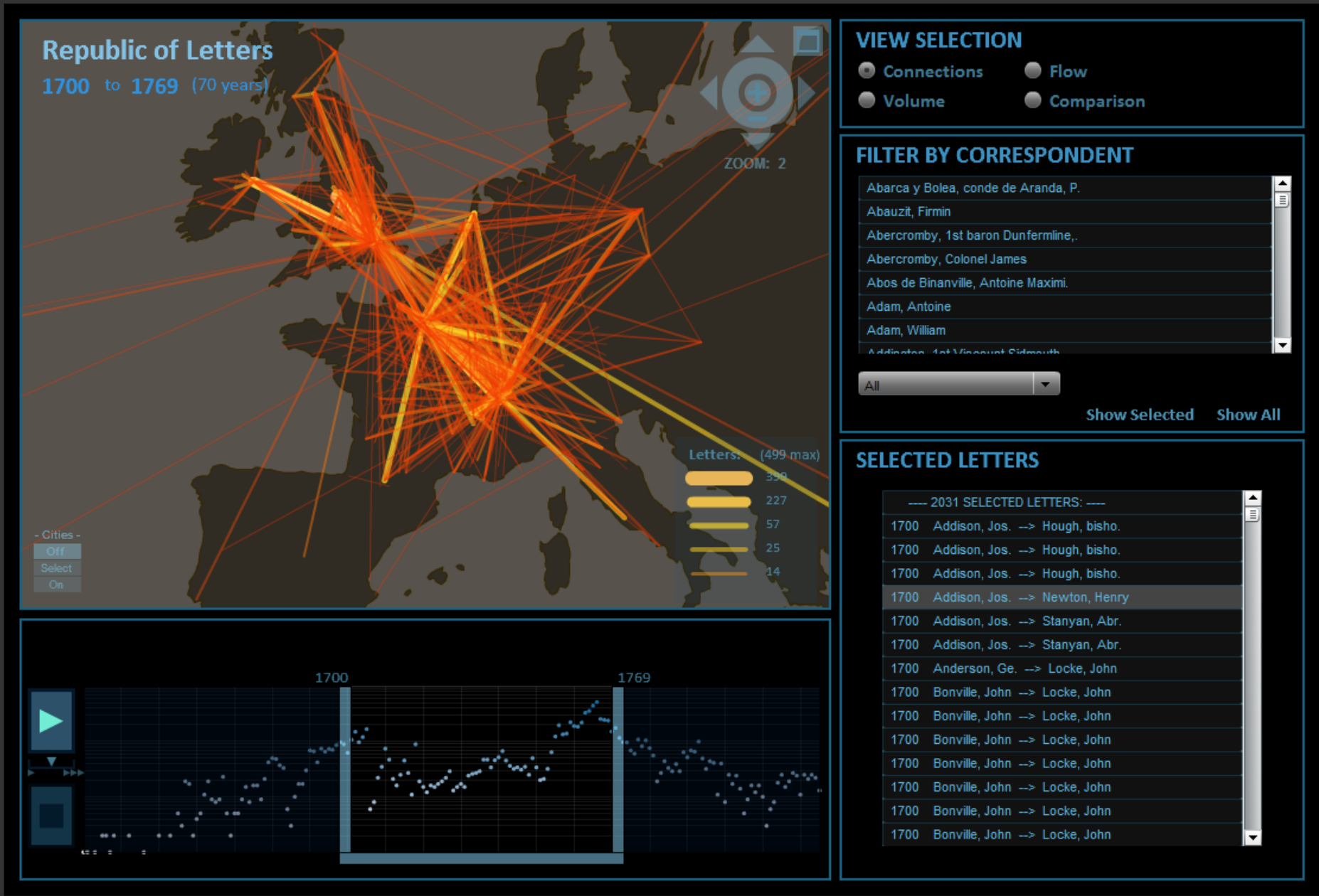

* Hold "Shift" and use mouse to select letters on a line

\section{Introduction}

Historians and other humanities scholars are increasingly seeking to develop and use visualization tools, methods, and theories for making sense of patterns in large sets of heterogeneous historical data with multiple dimensions. For example, the Electronic Enlightenment database of over 55,000 letters and documents exchanged between 6,400 correspondents in the Republic of Letters presents a typical challenge confronting the emerging field of digital humanities. How can humanities scholars trained in close reading of individual documents make sense of patterns in large sets of data?

\section{VISUALIZATION OF THE REPUBLIC OF LETTERS YUANKAI GE, DANIEL CHANG, AND SHIWEI SONG, STANFORD UNIVERSITY}

The Republic of Letters is an intellectual network of over 55,000 scholarly letters between 6,400 correspondents during the Enlightenment period, and spans the years 1629 to 1824 . Under the collaborative efforts of the Stanford Spatial History Lab and the Electronic Enlightenment database, we sought to visualize this giant corpus of data and explore how correspondences helped shape the European Enlightenment. The visualization as a tool provides historians with coarse- and fine-grain information filtering over space, time, and correspondents-down to the contents of each individual letter. Its primary goal is to enable historians to reveal insight and raise new questions about this crucial era in European history through visual representation of a historical database. 

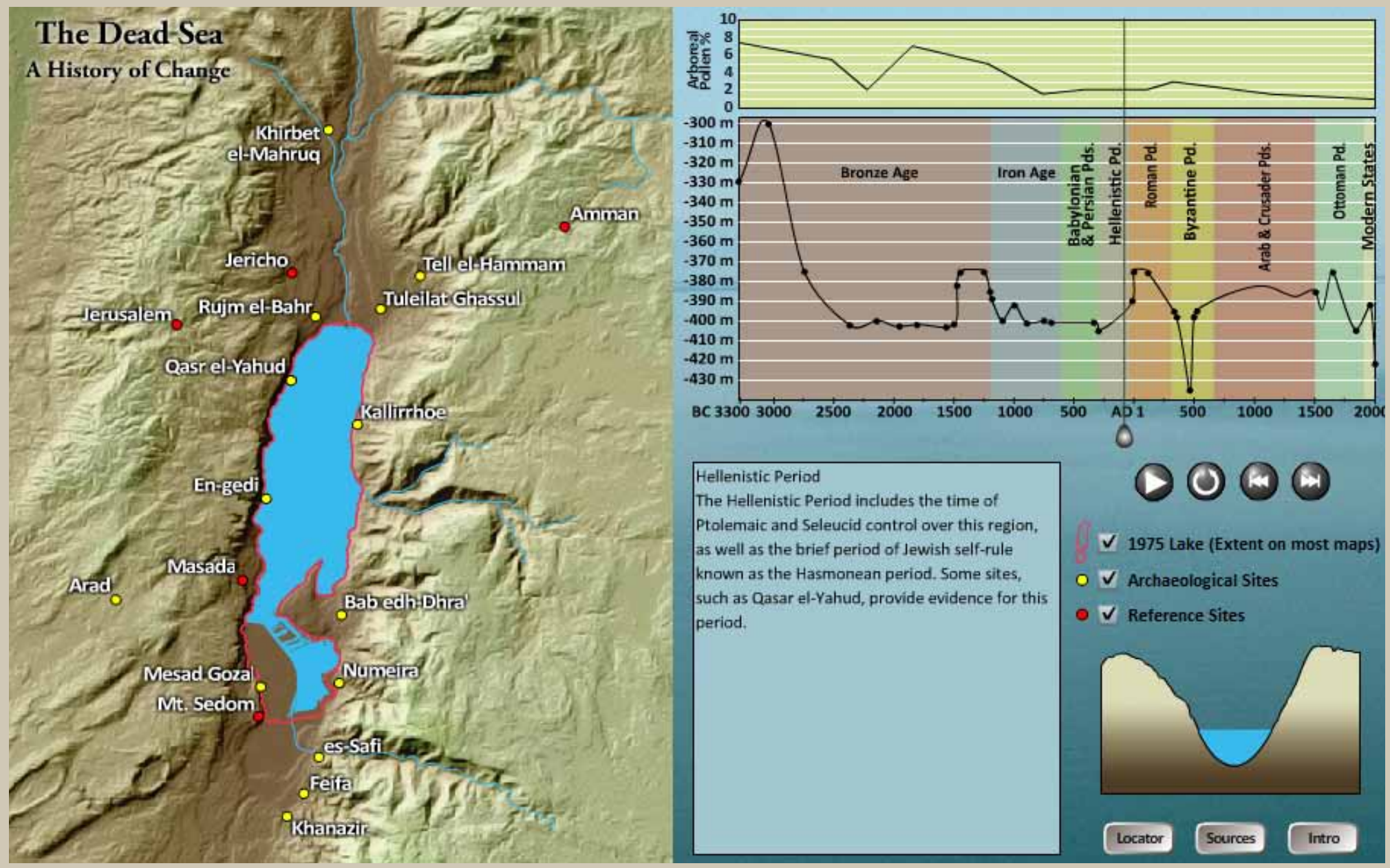

Hellenistic Period

The Hellenistic Period includes the time of Ptolemaic and Seleucid control over this region, as well as the brief period of Jewish self-rule known as the Hasmonean period. Some sites, such as Qasar el-Yahud, provide evidence for this period.

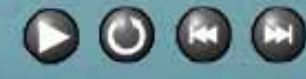

$\checkmark 1975$ Lake (Extent on most maps)

$\checkmark$ Archaeological Sites

$\checkmark$ Reference Sites

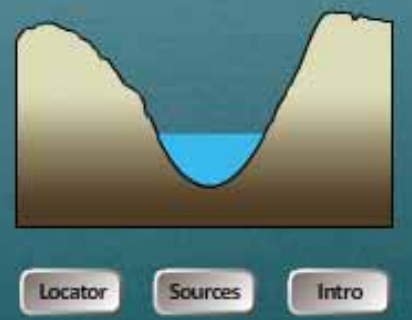

\section{THE DEAD SEA: A HISTORY OF CHANGE} A.D. RIDDLE AND DAVID PARKER, UNIVERSITY OF WISCONSIN-MADISON

"The Dead Sea: A History of Change" is an interactive, animated map that displays estimated levels of the Dead Sea throughout the Late Holocene epoch, specifically from 3500 B.C. to the present. The map includes a timeline of archaeological periods with a graph showing the estimated lake level, a corresponding pollen graph, a cross-section of the Dead Sea depression, and selection boxes for displaying on the map site locations and the 1975 lake level (which is the level that appears on most maps). The user is able to investigate the map further by scrolling over sites on the map, the archaeological periods on the timeline, or the pollen graph, and context-appropriate information will appear in the text field.

The conclusions presented in this map are drawn principally from an AAG paper by Barry Beitzel and various publications of Amos Frumkin, supplemented by additional sources. The level of the lake for a given period is deduced from the following kinds of evidence (when present): arboreal pollen counts, flood sediments and Aragonite deposits in caves, aggradation of wadi floodplains, dendrochronology and radiometric dating of organic remains, textual references, and the location of archaeological sites. The map will be of interest primarily to those who study paleoclimatology, Middle East archaeology, and/or historical geography. It suggests certain conclusions regarding regional climate throughout the Late Holocene, as well as the possible locations of ancient land and nautical transportation routes for the historical periods. 